\title{
The role of cobalt in bimetallic iron-cobalt magnetic carbon xerogels developed for catalytic wet peroxide oxidation
}

\author{
Rui S. Ribeiro ${ }^{\mathrm{a}, \mathrm{b}}$, Adrián M.T. Silva ${ }^{\mathrm{b}}$, José L. Figueiredo ${ }^{\mathrm{b}}$, Joaquim L. Faria ${ }^{\mathrm{b}}$, Helder T. Gomes ${ }^{\mathrm{a}, *}$

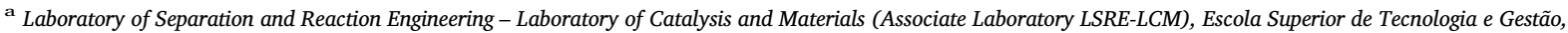 \\ Instituto Politécnico de Bragança, Campus de Santa Apolónia, 5300-253 Bragança, Portugal \\ b Laboratory of Separation and Reaction Engineering - Laboratory of Catalysis and Materials (Associate Laboratory LSRE-LCM), Faculdade de Engenharia, Universidade \\ do Porto, Rua Dr. Roberto Frias, 4200-465 Porto, Portugal
}

\section{A R T I C L E I N F O}

\section{Keywords:}

Heterogeneous Fenton-like process

Catalytic wet peroxide oxidation (CWPO)

Magnetic carbon composites

Bimetallic catalyst

Highly polluted waters

\begin{abstract}
A B S T R A C T
Three magnetic carbon xerogels were developed by inclusion of iron and/or cobalt precursors during the synthesis procedure. The synthesized materials were tested in the catalytic wet peroxide oxidation (CWPO) of aqueous solutions containing 4-nitrophenol (4-NP) - a refractory organic model pollutant, under a water treatment process intensification approach. For that purpose, the experimental runs were performed with high pollutant load $\left(5 \mathrm{~g} \mathrm{~L}^{-1}\right)$, low catalyst dosage $\left(2.5 \mathrm{~g} \mathrm{~L}^{-1}\right.$, corresponding to a fixed pollutant/catalyst mass ratio of 2), atmospheric pressure, $50{ }^{\circ} \mathrm{C}, \mathrm{pH}=3$ and stoichiometric amount of hydrogen peroxide $\left(\mathrm{H}_{2} \mathrm{O}_{2}\right)$.

The bimetallic magnetic carbon xerogel catalyst $(\mathrm{CX} / \mathrm{CoFe})$ was more active than each of the monometallic catalysts (CX/Fe or $\mathrm{CX} / \mathrm{Co}$ ). The better performance was explained in terms of a synergic association of factors: (i) the enhanced accessibility to the active iron species at the surface of $\mathrm{CX} / \mathrm{CoFe}$ promoted by the simultaneous incorporation of cobalt, (ii) the ability of metallic Co to catalyse $\mathrm{H}_{2} \mathrm{O}_{2}$ decomposition via hydroxyl radicals (HO ${ }^{\bullet}$ ) formation, and (iii) the efficient reduction of $\mathrm{Fe}^{3+}$ to $\mathrm{Fe}^{2+}$ promoted by metallic Co on the surface of $\mathrm{CX} / \mathrm{CoFe}$. A 4NP conversion of $98.5 \%$ was determined after $30 \mathrm{~min}$ of CWPO reaction. Leaching of the iron species in the bimetallic $\mathrm{CX} / \mathrm{CoFe}$ was considerably reduced with relation to the monometallic iron catalyst. However, partial catalyst deactivation occurred due to lower stability of oxidized cobalt species.

A detailed reaction mechanism is proposed for the surface catalytic reactions occurring over the $\mathrm{CX} / \mathrm{CoFe}$ catalyst.
\end{abstract}

\section{Introduction}

Catalytic wet peroxide oxidation (CWPO) is a recognized low cost advanced oxidation process (AOP) [1], typically operated with simple equipment and under mild conditions (e.g., at atmospheric pressure and low to moderate temperatures) [2]. Like other AOPs such as photocatalysis [3], ozonation [4], catalytic wet air oxidation [5], electrooxidation [6], persulfate oxidation [7], cavitation [8] and the Fenton process [9], CWPO relies on the formation of highly oxidizing hydroxyl radicals $\left(\mathrm{HO}^{\bullet}\right)$, which subsequently serve as effective species for the destruction of most of the organic pollutants present in aqueous phase $[10,11]$. In CWPO, $\mathrm{HO} \cdot$ are formed from the catalytic decomposition of hydrogen peroxide $\left(\mathrm{H}_{2} \mathrm{O}_{2}\right)$. When ferrous ion $\left(\mathrm{Fe}^{2+}\right)$ is used to catalyse the formation of $\mathrm{HO} \cdot$ from $\mathrm{H}_{2} \mathrm{O}_{2}$, the process is usually known as the Fenton process [12]. In this particular case, the main reactions involved in the catalytic cycle can be described by Eqs. (1) and (2). Briefly, the interaction between $\mathrm{H}_{2} \mathrm{O}_{2}$ and $\mathrm{Fe}^{2+}$ in acidic media results in the decomposition of $\mathrm{H}_{2} \mathrm{O}_{2}$ through the oxidation of $\mathrm{Fe}^{2+}$ to ferric ion $\left(\mathrm{Fe}^{3+}\right)$, with the formation of hydroxide ions $\left(\mathrm{OH}^{-}\right)$and $\mathrm{HO} \cdot$, as described by Eq. (1) $[12,13]$. Afterwards, the regeneration of $\mathrm{Fe}^{2+}$ from $\mathrm{Fe}^{3+}$ is mainly accomplished through the reaction of $\mathrm{Fe}^{3+}$ with $\mathrm{H}_{2} \mathrm{O}_{2}$, as described by Eq. (2) [13]. Nevertheless, the Fenton process includes several other reactions, resulting in a complex mechanism recently compiled by Munoz et al. [13]. For instance, the regeneration of $\mathrm{Fe}^{2+}$ from $\mathrm{Fe}^{3+}$ can also proceed through the reaction of $\mathrm{Fe}^{3+}$ with hydroperoxyl radicals (HOO•), as described in Eq. (3) [13-15].

$$
\begin{aligned}
& \mathrm{H}_{2} \mathrm{O}_{2}+\mathrm{Fe}^{2+} \rightarrow \mathrm{Fe}^{3+}+\mathrm{OH}^{-}+\mathrm{HO} \cdot \\
& \mathrm{Fe}^{3+}+\mathrm{H}_{2} \mathrm{O}_{2} \rightarrow \mathrm{Fe}^{2+}+\mathrm{HOO}+\mathrm{H}^{+} \\
& \mathrm{Fe}^{3+}+\mathrm{HOO} \bullet \rightarrow \mathrm{O}_{2}+\mathrm{H}^{+}+\mathrm{Fe}^{2+}
\end{aligned}
$$

However, some drawbacks leading to the increase of implementation and operation costs are commonly associated to the Fenton

\footnotetext{
* Corresponding author.

E-mail address: htgomes@ipb.pt (H.T. Gomes).
} 
process. One of them is the need for a complicated final separation step for the recovery or elimination of the $\mathrm{Fe}^{2+} / \mathrm{Fe}^{3+}$ ions, in many cases found in amounts exceeding the limits allowed by EU directives for discharge of treated water into natural receiving water bodies $\left(2 \mathrm{mg} \mathrm{L}^{-1}\right)$, which in turn leads to the undesired production of large amounts of iron sludge in the form of $\mathrm{Fe}(\mathrm{OH})_{3}[9,13]$. In this case, the costs associated to the subsequent treatment and disposal of the iron sludge may represent up to $50 \%$ of the total operating costs [13]. In order to overcome these constrains, the use of heterogeneous metal/ magnetic phases, either directly applied as catalyst in CWPO or included in very distinct support/hybrid materials, such as those containing alumina, silica, carbon materials, zeolites, pillared clays, minerals and others, have received a great deal of attention from the scientific community, as confirmed by several review articles published in recent years [11,13,16-22].

In the particular case of hybrid magnetic carbon materials, it has already been shown that several synergies arise from the combination of active and magnetically separable iron-based materials with the easily tuned properties of carbon-based materials [16]. As a result of these synergistic effects, the ability of CWPO to efficiently degrade toxic, persistent and bio-recalcitrant organic pollutants such as endocrine disrupting compounds, many types of pharmaceutical drugs, personal care products, pesticides, surfactants and biocides, has been demonstrated at atmospheric pressure and under mild temperatures (in the range $20-80{ }^{\circ} \mathrm{C}$ ) [16]. In addition, the confinement effect caused by the carbon phase promotes an increased structural stability of the nanostructured composites, leading to less leaching of metal species during CWPO [16]. Therefore, the typical separation step required in the classical Fenton process for the removal of dissolved iron species in the treated water can be avoided.

With all this in mind, novel magnetic carbon xerogels consisting of interconnected carbon microspheres with iron and/or cobalt microparticles embedded in their structure were recently developed and applied in the CWPO of an antimicrobial agent typically found throughout the urban water cycle - sulfamethoxazole [23]. It was observed that a synergistic effect arises from the simultaneous incorporation of cobalt and iron in the magnetic carbon xerogel (denoted as $\mathrm{CX} / \mathrm{CoFe}$ ), when its performance in the CWPO of sulfamethoxazole at the ppb level $\left(500 \mu \mathrm{g} \mathrm{L}^{-1}\right)$ is compared to that of monometallic catalysts containing only iron or cobalt [23]. However, this positive effect was not fully understood at that time. In the present work, the magnetic carbon xerogels were applied in the CWPO of 4-nitrophenol (4-NP) - a typical refractory organic model pollutant, under a water treatment process intensification approach. For that purpose, the CWPO experiments were performed with high pollutant load $\left(5 \mathrm{~g} \mathrm{~L}^{-1}\right)$ and low catalyst dosage $\left(2.5 \mathrm{~g} \mathrm{~L}^{-1}\right.$, corresponding to a fixed pollutant/catalyst mass ratio of 2, which is well higher than most of the ratios reported for the application of carbon [16] or magnetite-based [13] catalysts in CWPO). In this way, the synergistic effect previously observed is amplified, and the role of cobalt in the bimetallic iron-cobalt magnetic carbon xerogels can be fully clarified.

\section{Materials and methods}

\subsection{Chemicals}

4-Nitrophenol, 4-NP $\left(\mathrm{O}_{2} \mathrm{NC}_{6} \mathrm{H}_{4} \mathrm{OH}, \mathrm{Mr} 139.11,98\right.$ wt.\%) [CAS number: 100-02-7], hydrogen peroxide $\left(\mathrm{H}_{2} \mathrm{O}_{2}, 30 \% \mathrm{w} / \mathrm{v}\right)$ and ammonium acetate ( $98 \mathrm{wt} . \%$ ) were purchased from Acros Organics, Fluka and Pronalab, respectively. Resorcinol (99 wt.\%), cobalt (II) chloride hexahydrate (99 wt.\%), sodium hydroxide ( $98.7 \mathrm{wt} . \%)$, sulphuric acid (95 wt.\%), ascorbic acid (99 wt.\%), methanol (HPLC grade), glacial acetic acid (analytical reagent grade) and acetonitrile (HPLC grade) were obtained from Fisher Chemical. Formaldehyde solution (37 wt.\% in water, stabilized with $15 \mathrm{wt} . \%$ methanol), iron (III) chloride hexahydrate (97 wt.\%) and 1,10-phenantroline (99 wt.\%) were purchased from Panreac. Titanium (IV) oxysulphate $\left(\mathrm{TiOSO}_{4} \cdot \mathrm{xH}_{2} \mathrm{O}, 15\right.$ wt.\% in diluted sulphuric acid, 99.99\%), iron (II) chloride tetrahydrate and sodium sulphite ( $98 \mathrm{wt} . \%$ ) were purchased from Sigma-Aldrich.

All chemicals were used as received, without further purification. Distilled water was used throughout the work.

\subsection{Synthesis of magnetic carbon xerogels}

The magnetic carbon xerogels were prepared as described in our previous work, by inclusion of iron and/or cobalt precursors during the synthesis of carbon xerogels by polycondensation of resorcinol with formaldehyde [23].

\subsection{Characterization techniques}

The specific surface area $\left(S_{\mathrm{BET}}\right)$, micropore volume $\left(V_{\text {micro }}\right)$, total pore volume $\left(V_{\text {total }}\right)$, and the $\mathrm{pH}$ at point of zero charge $\left(\mathrm{pH}_{\mathrm{PZC}}\right)$ of the magnetic carbon xerogels were determined as previously described [23]. Likewise, the procedures used for the determination of the total contents of iron and cobalt in the magnetic carbon xerogels, to obtain scanning electron microscopy (SEM) images, and to perform X-ray photoelectron spectroscopy (XPS) analysis were also described in our previous publication [23]. In the case of the SEM measurements, ImageJ software was used in order to estimate the size of the primary carbon microspheres (at least 110 counts) and of the metal particles (at least 65 counts) embedded in the structure of the magnetic carbon xerogels. Regarding the XPS analysis, the oxidation states of iron and cobalt species were obtained from Fe 2p3/2 and Co 2p3/2 spectral fitting with Lorentz curves using the OriginPro software, based on the spectral fitting parameters reported elsewhere [24], namely binding energies and full width at half maximum (FWHM) values for $\mathrm{Fe}, \mathrm{FeO}$, $\mathrm{Fe}_{2} \mathrm{O}_{3}$, Co, $\mathrm{CoO}$ and $\mathrm{CoOOH}$ reference samples.

\subsection{Catalytic wet peroxide oxidation experiments}

Batch CWPO experiments were performed as previously described [25], with [4-NP] $]_{0}=5 \mathrm{~g} \mathrm{~L}^{-1}, \quad$ [catalyst $]=2.5 \mathrm{~g} \mathrm{~L}^{-1}, \quad T=50^{\circ} \mathrm{C}$, $\mathrm{pH}=3$ and $\left[\mathrm{H}_{2} \mathrm{O}_{2}\right]_{0}=\left[\mathrm{H}_{2} \mathrm{O}_{2}\right]_{\text {Stoichiometric }}=17.8 \mathrm{~g} \mathrm{~L}^{-1}$. Pure adsorption runs were performed by replacing the amount of $\mathrm{H}_{2} \mathrm{O}_{2}$ with distilled water. All the experiments were performed considering the mass ratio $[4-\mathrm{NP}]_{0} /[$ catalyst/adsorbent $]=2$. Blank experiments were carried out in the absence of catalyst. Homogeneous CWPO runs were performed using iron (II) chloride tetrahydrate and cobalt (II) chloride hexahydrate as source of $\mathrm{Fe}^{2+}$ and $\mathrm{Co}^{2+}$, respectively.

Selected experiments were performed in triplicate, in order to assess reproducibility and error of the experimental results. It was found that the relative standard deviations of 4-NP and $\mathrm{H}_{2} \mathrm{O}_{2}$ determination were never higher than $3 \%$ and $2 \%$, respectively.

\subsection{Analytical methods}

The parent compound 4-NP and possible oxidation by-products were determined by high performance liquid chromatography (HPLC), using a previously described method [26]. Total organic carbon (TOC) was determined using a Shimadzu TOC-L CSN analyser. In both cases, sodium sulphite was used in order to consume residual $\mathrm{H}_{2} \mathrm{O}_{2}$ [26]. The concentration of $\mathrm{H}_{2} \mathrm{O}_{2}$ [26] and the dissolved iron content [23] were determined by colorimetric methods, while the dissolved cobalt was determined by atomic absorption spectroscopy [23].

\section{Results and discussion}

\subsection{Textural and surface chemical characterization}

The magnetic carbon xerogels used in this work were extensively characterized in a previous publication for their application in the 

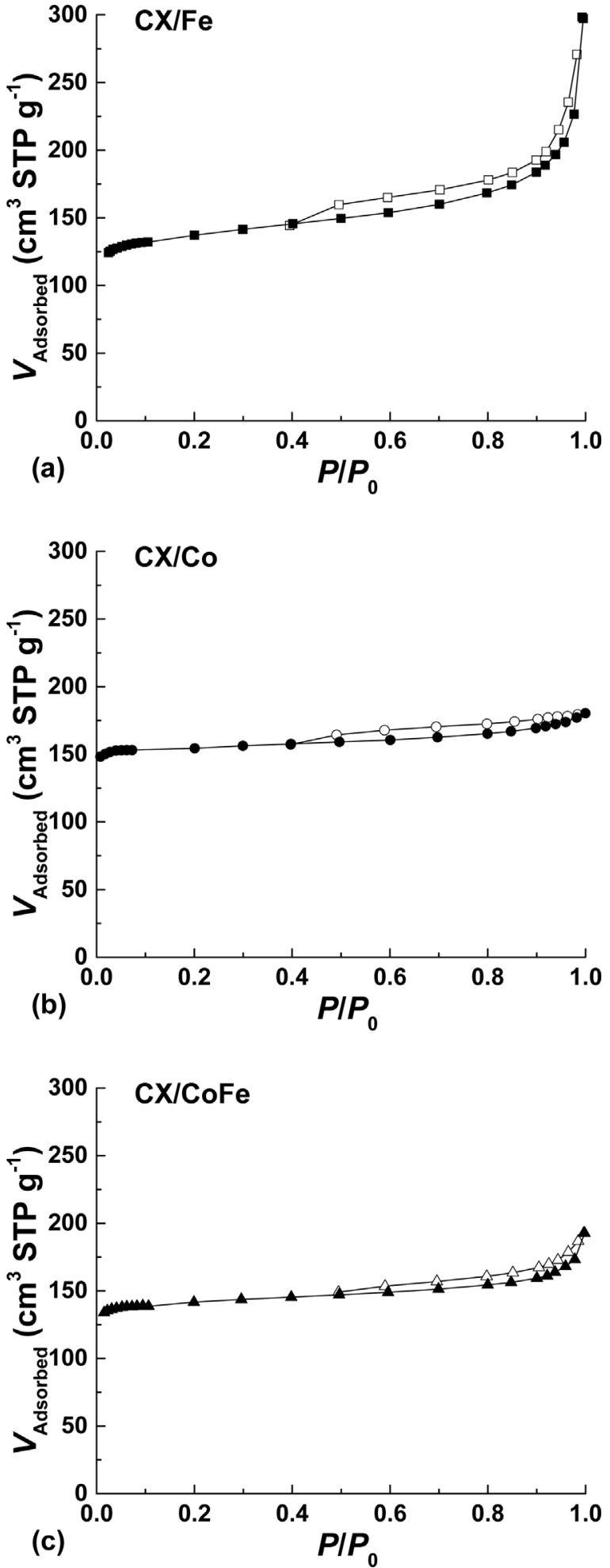

Fig. 1. $\mathrm{N}_{2}$ adsorption-desorption isotherms at $-196^{\circ} \mathrm{C}$ of (a) $\mathrm{CX} / \mathrm{Fe},(\mathrm{b}) \mathrm{CX} / \mathrm{Co}$ and (c) $\mathrm{CX} / \mathrm{CoFe}$.

CWPO of the antimicrobial agent sulfamethoxazole [23]. Notwithstanding, some textural and surface chemical properties were further explored throughout this work.

The textural properties of the magnetic carbon xerogels were determined from the $\mathrm{N}_{2}$ adsorption-desorption isotherms given in Fig. 1 . The material resulting from the inclusion of iron during the polymerization step $(\mathrm{CX} / \mathrm{Fe})$ denotes a stronger influence of mesoporosity (as revealed by the progressive increase of the amount of $\mathrm{N}_{2}$ adsorbed at
Table 1

Properties of the magnetic carbon xerogels: specific surface area $\left(S_{\mathrm{BET}}\right)$, total pore volume $\left(V_{\text {total }}\right)$, micropore volume $\left(V_{\text {micro }}\right), \mathrm{pH}$ at the point of zero charge $\left(\mathrm{pH}_{\mathrm{PzC}}\right)$, average size of the primary carbon microspheres $\left(d_{\text {carbon }}\right)$ and average size of the metal particles $\left(d_{\text {metal }}\right)$.

\begin{tabular}{|c|c|c|c|c|c|c|}
\hline \multirow[t]{2}{*}{ Material } & \multicolumn{6}{|l|}{ Parameter } \\
\hline & $\begin{array}{l}S_{\mathrm{BET}} \\
\left(\mathrm{m}^{2} \mathrm{~g}^{-1}\right)\end{array}$ & $\begin{array}{l}V_{\text {total }} \\
\left(\mathrm{cm}^{3} \mathrm{~g}^{-1}\right)\end{array}$ & $\begin{array}{l}V_{\text {micro }} \\
\left(\mathrm{cm}^{3} \mathrm{~g}^{-1}\right)\end{array}$ & $\mathrm{pH}_{\mathrm{PZC}}$ & $d_{\text {carbon }}(\mu \mathrm{m})$ & $d_{\text {metal }}(\mu \mathrm{m})$ \\
\hline $\mathrm{CX} / \mathrm{Fe}$ & 510 & 0.46 & 0.17 & 6.6 & $0.9 \pm 0.3$ & $0.7 \pm 0.4$ \\
\hline $\mathrm{CX} / \mathrm{Co}$ & 580 & 0.28 & 0.23 & 8.3 & $2.7 \pm 0.4$ & $1.2 \pm 0.2$ \\
\hline $\mathrm{CX} / \mathrm{CoFe}$ & 530 & 0.30 & 0.20 & 7.7 & $2.1 \pm 0.4$ & $1.3 \pm 0.6$ \\
\hline
\end{tabular}

higher relative pressures). On the other hand, the material with only cobalt in its structure $(\mathrm{CX} / \mathrm{Co})$ is essentially microporous (as revealed by the amount of $\mathrm{N}_{2}$ adsorbed at low relative pressure). The bimetallic magnetic carbon xerogel $(\mathrm{CX} / \mathrm{CoFe})$ exhibits intermediate textural properties, as detailed in Table 1 . In addition to the specific surface area $\left(S_{\mathrm{BET}}\right)$, the intermediate properties of $\mathrm{CX} / \mathrm{CoFe}$ are particularly reflected by the ratio $V_{\text {micro }} / V_{\text {total }}$. Specifically, $\mathrm{CX} / \mathrm{Fe}$ reveals a ratio $V_{\text {micro }} /$ $V_{\text {total }}=0.37$, while $\mathrm{CX} /$ Co reveals a more pronounced microporous nature $\left(V_{\text {micro }} / V_{\text {total }}=0.81\right) ; \mathrm{CX} / \mathrm{CoFe}$ reveals an intermediate ratio $V_{\text {micro }} / V_{\text {total }}=0.68$.

The molecular structure of the magnetic carbon xerogels was analysed by XRD in our previous publication [23]. It was found that the magnetic carbon xerogels are composed of graphite and iron and/or cobalt species. Specifically, magnetite $\left(\mathrm{Fe}_{3} \mathrm{O}_{4}\right.$; with a lattice parameter $a=8.380 \AA$ ) and metallic iron (Fe; $a=2.868 \AA$ ) were identified in the diffraction pattern of $\mathrm{CX} / \mathrm{Fe}$ in addition to graphite. In the case of $\mathrm{CX} /$ Co, metallic cobalt (Co; $a=3.544 \AA$ ), cobalt (II, III) oxide $\left(\mathrm{Co}_{3} \mathrm{O}_{4}\right.$; $a=8.089 \AA$ ) and cobalt (II) oxide ( $\mathrm{CoO} ; a=4.268 \AA$ ) were identified in addition to graphite. On the other hand, cobalt ferrite $\left(\mathrm{CoFe}_{2} \mathrm{O}_{4}\right.$; $a=8.388 \AA)$ and Fe $(a=2.863 \AA)$ were observed in the diffraction pattern of $\mathrm{CX} / \mathrm{CoFe}$ in addition to graphite.

Regarding the surface chemistry, the values of $\mathrm{pH}_{\mathrm{PZC}}$ of the magnetic carbon xerogels were determined (cf. Table 1). As discussed in our previous study, the values of $\mathrm{pH}_{\mathrm{PZC}}$ follow the same order of those reported in the literature for their main metal oxide constituents, suggesting that the $\mathrm{pH}_{\mathrm{PZC}}$ of the magnetic carbon xerogels are mainly determined by the different contributions of the metal oxides detected by XRD [23]. Additional insights on the oxidation state of each component existing at the surface of the magnetic carbon xerogels were obtained by XPS analysis, as discussed in Section 3.2.3.

The morphology of the magnetic carbon xerogels was analysed by SEM (Fig. 2). These materials are composed by aggregates of interconnected carbon microspheres with metal microparticles embedded in their structure (composed of iron and/or cobalt species, as previously discussed). The monometallic CX/Fe (Fig. 2a) possesses the largest and more complex aggregates, but the smallest primary carbon microspheres (cf. Table 1); on the contrary, the monometallic CX/Co (Fig. 2b) possesses the smallest aggregates, but the largest carbon microspheres. The characteristics of the aggregates and carbon microspheres of the bimetallic $\mathrm{CX} / \mathrm{CoFe}$ fall between those observed with the monometallic materials (Fig. 2c).

The presence of cobalt (i.e., $\mathrm{CX} / \mathrm{Co}$ and $\mathrm{CX} / \mathrm{CoFe}$ ) leads to a more pronounced distribution of the metallic phase over the surface of the magnetic carbon xerogels (Fig. 2). To confirm this observation, the total contents of the different metal species embedded in the magnetic carbon xerogels were determined by atomic absorption analysis of the solutions resulting from the acidic digestion of the solids.

As observed in Table 2, $\mathrm{CX} / \mathrm{Fe}$ and $\mathrm{CX} / \mathrm{CoFe}$ contain about the same total metal fraction $(6.5 \% \mathrm{Fe}$ vs. $4.6 \% \mathrm{Fe}+2.1 \%$ Co, i.e., $6.7 \%$ metal phase). However, the amount and distribution of metal particles on the surface of $\mathrm{CX} / \mathrm{CoFe}$ (Fig. 2c) is more evident than that observed with $\mathrm{CX} / \mathrm{Fe}$ (Fig. 2a). For the sake of clarity, the metal distribution at the surface of the magnetic carbon xerogels was analysed by XPS. The 

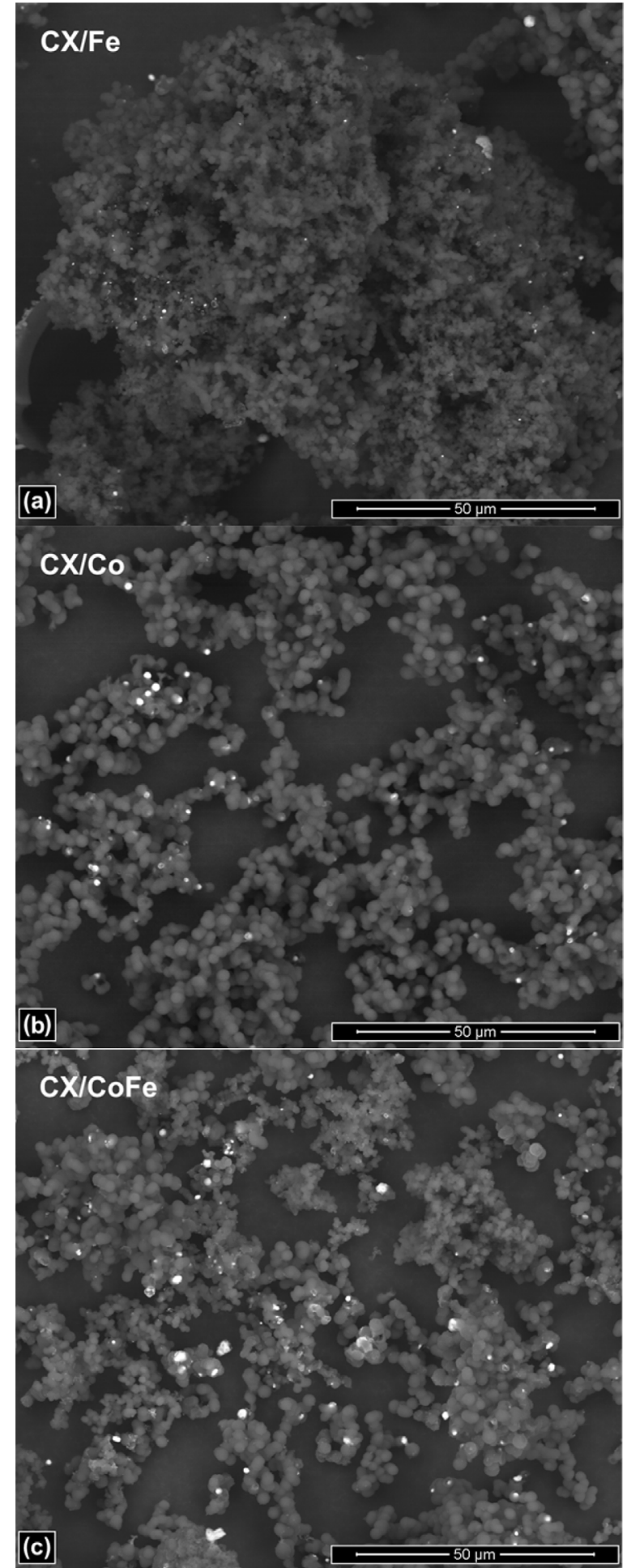

Fig. 2. SEM micrographs of (a) $\mathrm{CX} / \mathrm{Fe}$, (b) $\mathrm{CX} / \mathrm{Co}$ and (c) $\mathrm{CX} / \mathrm{CoFe}$, obtained in backscattered electron detection mode.

corresponding atomic surface concentrations of $\mathrm{C}, \mathrm{O}, \mathrm{Fe}$ and Co are also given in Table 2. As observed, the simultaneous incorporation of iron and cobalt leads to an increased metal concentration at the surface of the bimetallic $\mathrm{CX} / \mathrm{CoFe}$, confirming that the distribution of metal particles at the surface of the magnetic carbon xerogels is affected by the nature of the metal precursor. The differences observed between the total iron and cobalt contents given in Table 2 when compared to the surface weight concentrations (also given in Table 2), can be ascribed to the encapsulation of metal particles by the organic phase during the
Table 2

Metal content of the magnetic carbon xerogels: total content of $\mathrm{Fe}$ and $\mathrm{Co}$, as determined by atomic absorption analysis of the solutions resulting from the acidic digestion of the solids; and weight surface concentration of $\mathrm{C}, \mathrm{O}, \mathrm{Fe}$ and $\mathrm{Co}$, as determined from XPS analysis.

\begin{tabular}{|c|c|c|c|c|c|c|}
\hline \multirow[t]{2}{*}{ Material } & \multicolumn{2}{|c|}{ Total content (wt.\%) } & \multicolumn{4}{|c|}{ Atomic surface concentration (wt.\%) } \\
\hline & $\mathrm{Fe}$ & Co & $\mathrm{C}$ & $\mathrm{O}$ & $\mathrm{Fe}$ & Co \\
\hline $\mathrm{CX} / \mathrm{Fe}$ & 6.5 & - & 79.00 & 17.97 & 3.03 & - \\
\hline $\mathrm{CX} / \mathrm{Co}$ & - & 0.9 & 84.95 & 12.91 & - & 2.14 \\
\hline $\mathrm{CX} / \mathrm{CoFe}$ & 4.6 & 2.1 & 76.01 & 16.33 & 4.97 & 2.69 \\
\hline
\end{tabular}

synthesis of the monometallic materials. On the contrary, as suggested by the higher surface concentrations of both iron and cobalt when compared to their total contents (cf. Table 2), the metals are preferentially located at the surface of the magnetic carbon xerogel when iron and cobalt are simultaneously incorporated in the bimetallic CX/ $\mathrm{CoFe}$, therefore becoming more accessible.

\subsection{Catalytic wet peroxide oxidation experiments}

The performance of the magnetic carbon xerogels in the CWPO of highly concentrated 4-NP solutions $\left(5 \mathrm{~g} \mathrm{~L}^{-1}\right)$ was evaluated in experiments performed under the conditions referred in Section 2.4. The corresponding 4-NP removal curves are shown in Fig. 3. These results confirm the superior performance of the bimetallic magnetic carbon xerogel with cobalt and iron microparticles embedded in its structure ( $\mathrm{CX} / \mathrm{CoFe}$ ), when compared to the performance of the monometallic catalysts containing only iron $(\mathrm{CX} / \mathrm{Fe})$ or cobalt $(\mathrm{CX} / \mathrm{Co})$. Specifically, $98.5 \%$ of the initial 4-NP content is removed after $30 \mathrm{~min}$ in the presence of $\mathrm{CX} / \mathrm{CoFe}$, representing a pollutant mass removal of $3940 \mathrm{mg} \mathrm{g}^{-1} \mathrm{~h}^{-1}$, which is higher than most of the values reported in the literature for carbon-based and magnetite-based catalysts $[13,16,25]$.

Given its potential catalytic activity (Eqs. (1)-(3)), the iron leached to the treated water during the CWPO runs performed with $\mathrm{CX} / \mathrm{Fe}$ and $\mathrm{CX} / \mathrm{CoFe}$ (the magnetic carbon xerogels containing iron species) was determined. It was observed that the iron leached from $\mathrm{CX} / \mathrm{Fe}$ amounts to $8.69 \mathrm{mg} \mathrm{L}^{-1}$. On the contrary, $\mathrm{CX} / \mathrm{CoFe}$ reveals a much better resistance to leaching, with an amount of leached iron of $0.67 \mathrm{mg} \mathrm{L}^{-1}$ at the end of the CWPO treatment, a value well below the limit of $2 \mathrm{mg} \mathrm{L}^{-1}$ allowed by common EU directives regulating the discharge of treated waters into natural water bodies.

Up to this point, the catalytic performance of $\mathrm{CX} / \mathrm{CoFe}$ allows to confirm the synergy - arising from the simultaneous inclusion of iron and cobalt - observed previously in the CWPO of sulfamethoxazole

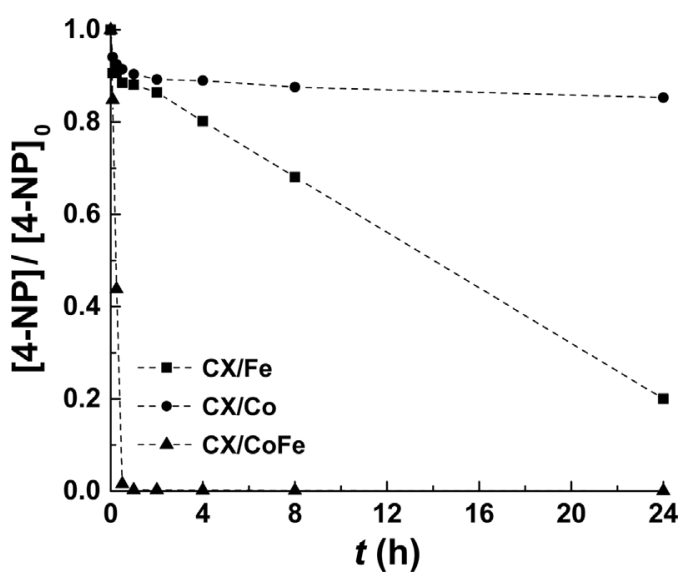

Fig. 3. Removal of 4-NP obtained as a function of time in CWPO runs performed with the magnetic carbon xerogels. Experiments performed with [4-NP] $]_{0}=5 \mathrm{~g} \mathrm{~L}^{-1}$, [catalyst] $=2.5 \mathrm{~g} \mathrm{~L}^{-1}, T=50^{\circ} \mathrm{C}, \mathrm{pH}=3$ and $\left[\mathrm{H}_{2} \mathrm{O}_{2}\right]_{0}=\left[\mathrm{H}_{2} \mathrm{O}_{2}\right]_{\text {Stoichiometric }}=17.8 \mathrm{~g} \mathrm{~L}^{-1}$. 

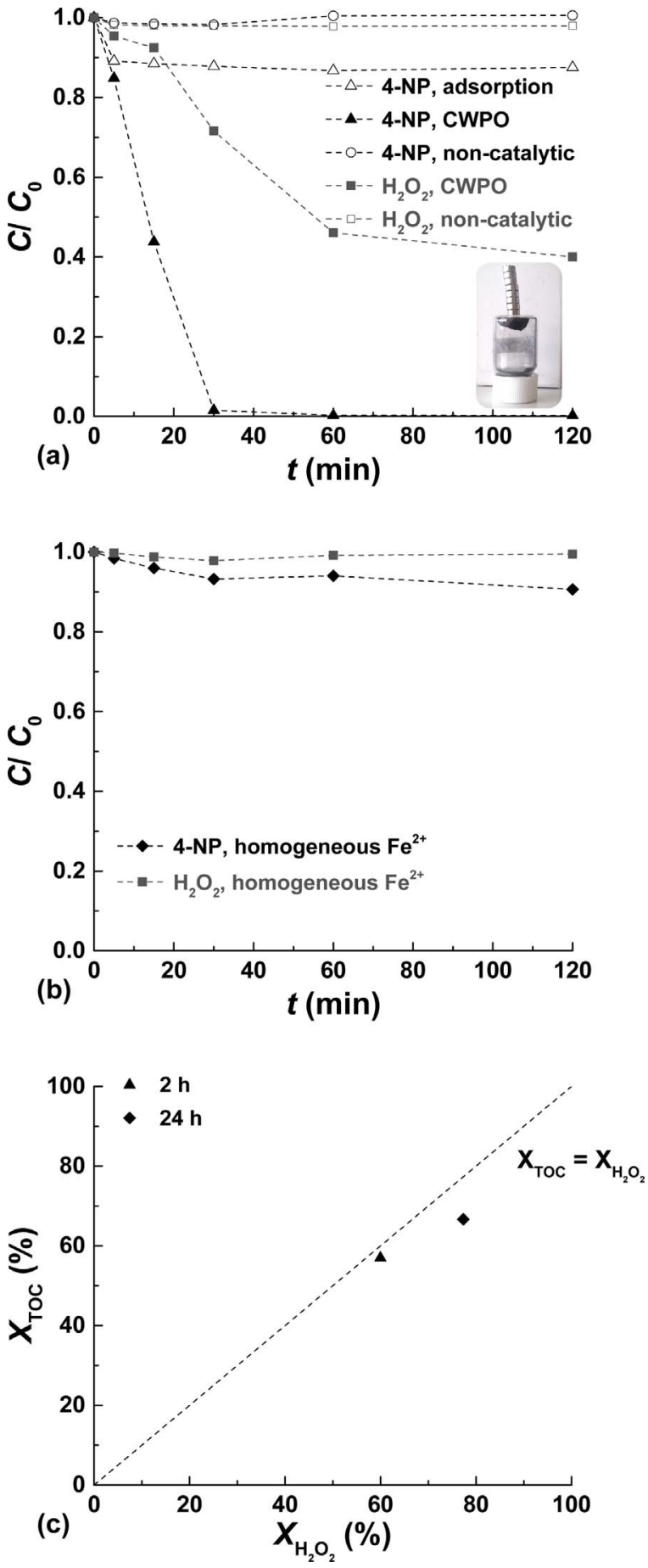

Fig. 4. (a) 4-NP and $\mathrm{H}_{2} \mathrm{O}_{2}$ conversions as a function of time in the CWPO run performed with $\mathrm{CX} / \mathrm{CoFe}$, and in the non-catalytic run performed in the absence of catalyst (Inset: magnetic sensitivity of the bimetallic CX/CoFe catalyst); 4-NP removal by adsorption is also shown for comparison. (b) 4-NP and $\mathrm{H}_{2} \mathrm{O}_{2}$ conversions as a function of time in the homogeneous CWPO run performed with $\mathrm{Fe}^{2+}\left(0.67 \mathrm{mg} \mathrm{L}^{-1}\right.$, corresponding to the amount leached during the CWPO of 4-NP in the presence of CX/CoFe). (c) TOC vs $\mathrm{H}_{2} \mathrm{O}_{2}$ conversions obtained after 2 and $24 \mathrm{~h}$ of CWPO in the presence of $\mathrm{CX} / \mathrm{CoFe}$. Experiments performed under the operating conditions given in Fig. 3.

[23]. At that time, this effect was solely ascribed to an enhanced accessibility to the active iron species existing at the surface of $\mathrm{CX} / \mathrm{CoFe}$, promoted by the simultaneous incorporation of cobalt, such as discussed in previous Section 3.1. However, the additional fact that iron leaching was much lower (about 13-fold lower, for the catalyst CX/ CoFe $\left(0.67 \mathrm{mg} \mathrm{L}^{-1}\right)$, when compared to the catalyst $\mathrm{CX} / \mathrm{Fe}$
(8.69 $\mathrm{mg} \mathrm{L}^{-1}$ ), under the same experimental conditions) cannot be explained only in terms of the bimetallic interaction during the synthesis. Bearing this in mind, additional experiments were conducted seeking to clarify the nature of the mechanisms and interactions between the different metallic phases, which can be held responsible for the superior performance of $\mathrm{CX} / \mathrm{CoFe}$, when compared to the monometallic catalysts.

The role of heterogeneous catalysis promoted by $\mathrm{CX} / \mathrm{CoFe}$ was thus the object of a detailed study (Fig. 4). The influence of adsorption in the global performance of the $\mathrm{CX} / \mathrm{CoFe}$ catalyst was evaluated in a pure adsorption run. As observed in Fig. 4a, the removal of 4-NP by CWPO in the presence of $\mathrm{CX} / \mathrm{CoFe}$ is markedly higher than the removal by pure adsorption. Moreover, the removal of 4-NP in the absence of a catalyst (non-catalytic) is null after $2 \mathrm{~h}$ of reaction. In order to understand if the iron leached to the solution could be responsible for the removals of 4$\mathrm{NP}$ observed, the effect of homogeneous catalysis promoted by the amount of iron leached during CWPO was simulated using a Fe ${ }^{2+}$ solution as catalyst. This solution contained the same concentration of iron as the iron leached in the CWPO experiment performed with CX/ $\mathrm{CoFe}$ (i.e., $0.67 \mathrm{mg} \mathrm{L}^{-1}$ ). This contribution, shown in Fig. 4b, represents 4-NP and TOC removals of only $9.4 \%$ and $2.3 \%$, respectively. Likewise, the possible effect of cobalt leaching was also considered negligible (this issue will be discussed in detail in Section 3.2.3). Taking into consideration these results, it can be clearly established that the contributions of pure adsorption, non-catalytic and homogeneous catalytic removals are negligible, confirming that $\mathrm{CX} / \mathrm{CoFe}$ is very active as a heterogeneous catalyst for the CWPO of highly concentrated 4-NP solutions under mild operating conditions. In addition, the magnetic sensitivity of CX/CoFe (inset of Fig. 4a) opens prospects for the development of in-situ magnetic separation systems.

Regarding the mineralization of $4-\mathrm{NP}$, ca. $57 \%$ of TOC removal is achieved upon application of the bimetallic CX/CoFe catalyst during $2 \mathrm{~h}-\mathrm{a}$ value that increases up to ca. $67 \%$ when the CWPO experiment is allowed to proceed during $24 \mathrm{~h}$. To evaluate the efficiency of $\mathrm{H}_{2} \mathrm{O}_{2}$ consumption when CX/CoFe is applied in the CWPO of 4-NP, the TOC conversion $\left(X_{\mathrm{TOC}}\right)$ was plotted against the $\mathrm{H}_{2} \mathrm{O}_{2}$ conversion $\left(X_{\mathrm{H} 2 \mathrm{O} 2}\right)$ obtained after 2 and $24 \mathrm{~h}$ of reaction (cf. Fig. 4c). As observed, the values of $X_{\mathrm{TOC}}$ are similar to those of $X_{\mathrm{H} 2 \mathrm{O} 2}$, suggesting high efficiency of TOC removal per unit of $\mathrm{H}_{2} \mathrm{O}_{2}$ decomposed $\left(\eta_{\mathrm{H} 2 \mathrm{O} 2}\right)$. Specifically, the values of $\eta_{\mathrm{H} 2 \mathrm{O} 2}$ are in the range $86-95 \%$. Therefore, it is possible to conclude that, in addition to the high performance of the catalyst, the $\mathrm{H}_{2} \mathrm{O}_{2}$ employed in the CWPO of highly concentrated 4-NP solutions with $\mathrm{CX} / \mathrm{CoFe}$ is also consumed with high efficiency.

\subsubsection{Oxidation mechanism}

The reaction mechanism of $\mathrm{HO} \bullet$ with aromatic compounds proceeds mainly through an electrophilic addition to the aromatic ring [27-29]. In the particular case of 4-NP, it was shown in previous works that the presence of the phenolic $-\mathrm{OH}$ group together with the $-\mathrm{NO}_{2}$ group, is favourable to an electrophilic attack at the ortho position in respect to the $-\mathrm{OH}$ group, leading to the formation of 4-nitrocatechol $[25,26]$. Nevertheless, hydroquinone, 1,4-benzoquinone and catechol can also be formed, in accordance with the oxidation mechanism previously proposed [26]. In order to confirm the oxidation/mineralization mechanism, the evolution of possible aromatic by-products was assessed in the experiments performed with the two magnetic samples exhibiting the highest activity. Accordingly, the performances of CX/Fe and CX/ CoFe are shown in Fig. $5 \mathrm{a}$ and b, respectively. Regardless of the catalyst employed, the mineralization of 4-NP by CWPO proceeds as expected, mainly via formation of 4-nitrocatechol; even if hydroquinone, 1,4benzoquinone and catechol are also detected. However, the aromatic by-products of 4-NP CWPO are accumulated in solution when $\mathrm{CX} / \mathrm{Fe}$ is applied (cf. Fig. 5a); while, in the opposite, the aromatic by-products of 4-NP CWPO are readily mineralized in the presence of the bimetallic $\mathrm{CX} / \mathrm{CoFe}$ catalyst (cf. Fig. 5b). Therefore, it is possible to conclude that the superior performance previously evidenced by $\mathrm{CX} / \mathrm{CoFe}$ regarding 

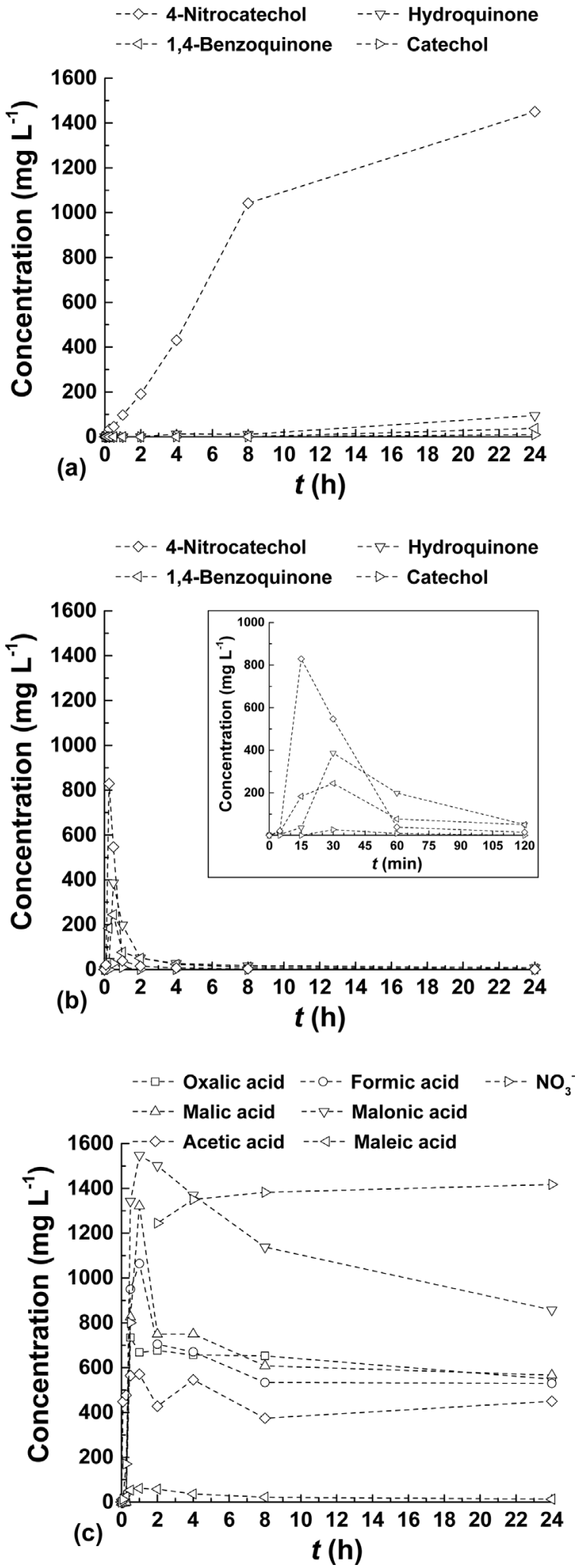

Fig. 5. Evolution of aromatic by-products of 4-NP oxidation, when using (a) CX/Fe and (b) $\mathrm{CX} / \mathrm{CoFe}$ (Inset: $\mathrm{x}$-axis with maximum of $120 \mathrm{~min}=2 \mathrm{~h}$ ); and (c) evolution of nonaromatic by-products of 4-NP oxidation when using CX/CoFe in the CWPO of 4-NP $\left(5 \mathrm{~g} \mathrm{~L}^{-1}\right)$. Experiments performed under the operating conditions given in Fig. 3.

4-NP removal is also reflected on the subsequent steps of 4-NP mineralization.

The evolution of possible non-aromatic by-products was assessed in the experiment performed with $\mathrm{CX} / \mathrm{CoFe}$, in order to confirm the
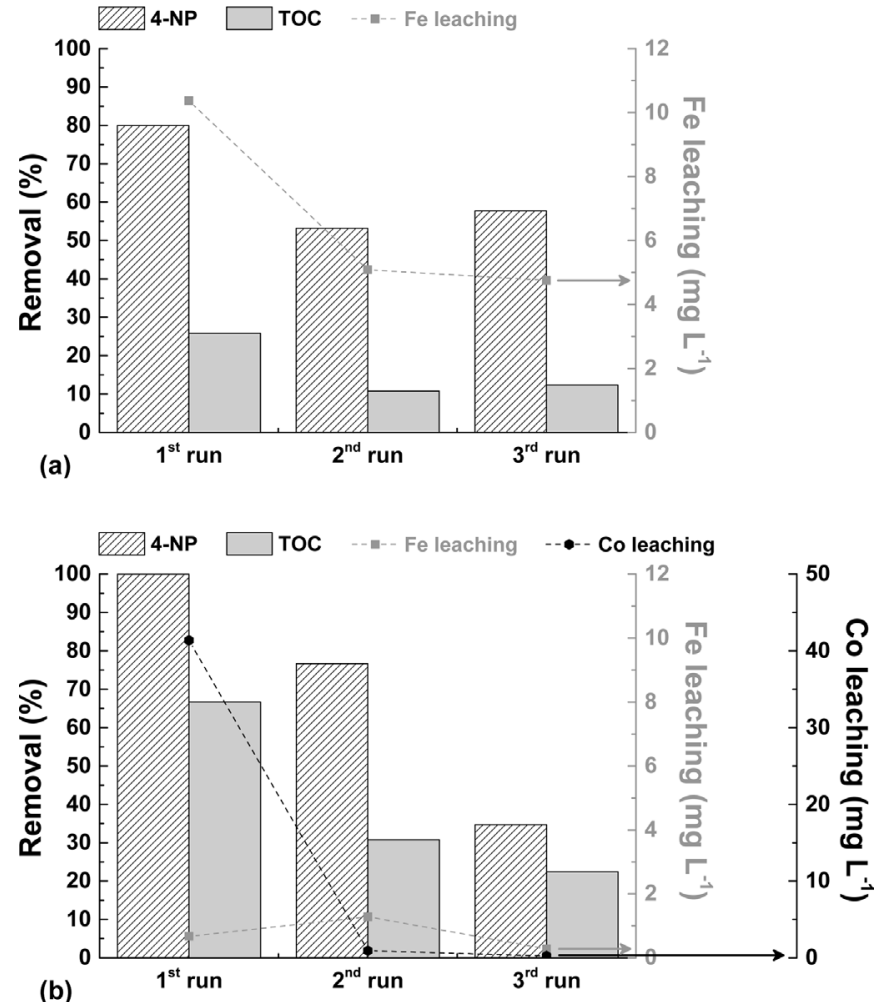

Fig. 6. 4-NP and TOC conversions [left axis] and corresponding iron and cobalt leaching [right axis] obtained in a series of three consecutive CWPO runs performed with (a) CX/ $\mathrm{Fe}$ and (b) $\mathrm{CX} / \mathrm{CoFe}$ during $24 \mathrm{~h}$ under the operating conditions given in Fig. 3.

formation of ring-opening products as the aromatic by-products are further attacked by $\mathrm{HO} \cdot$. As observed in Fig. 5c, several low molecular weight carboxylic acids were detected. Nitrate produced from the $-\mathrm{NO}_{2}$ group of the 4-NP aromatic ring was also detected, confirming the $-\mathrm{NO}_{2}$ group abstraction from the main aromatic rings through CWPO in the presence of $\mathrm{CX} / \mathrm{CoFe}$.

\subsubsection{Reusability cycles}

Two series of three consecutive CWPO runs were performed with $\mathrm{CX} / \mathrm{Fe}$ and $\mathrm{CX} / \mathrm{CoFe}$ in order to evaluate the effect of the simultaneous incorporation of cobalt and iron on the stability of the catalysts. For that purpose, the catalyst was filtered after each run, washed and dried at $60{ }^{\circ} \mathrm{C}$ overnight, and then reused in CWPO with a fresh 4-NP solution. As observed in Fig. 6, both magnetic carbon xerogels undergo partial deactivation upon successive reuse in CWPO cycles. This phenomenon results from the water treatment process intensification approach used in this work, which was employed in order to amplify the synergistic effect arising from the simultaneous inclusion of iron and cobalt in the $\mathrm{CX} / \mathrm{CoFe}$ catalyst. The CWPO experiments were performed with high pollutant load $\left(5 \mathrm{~g} \mathrm{~L}^{-1}\right)$ and low catalyst dosage $\left(2.5 \mathrm{~g} \mathrm{~L}^{-1}\right)$, allowing to promote very harsh conditions in the catalytic system, especially as several by-products of 4-NP oxidation are formed. As observed in Fig. 5c, several low molecular weight carboxylic acids are formed during the CWPO of 4-NP under the operating conditions employed. After the initial adjustment, the experiments were allowed to proceed without further conditioning of $\mathrm{pH}$. Therefore, the $\mathrm{pH}$ of the treated water dropped from 3.0 to 2.5 and 2.0, in the CWPO experiments performed with $\mathrm{CX} / \mathrm{Fe}$ and $\mathrm{CX} / \mathrm{CoFe}$, respectively. In spite of the substantially higher decrease of the solution $\mathrm{pH}$, the $\mathrm{CX} / \mathrm{CoFe}$ catalyst reveals a much better resistance against the leaching of iron species to the treated water throughout the three reusability cycles considered (cf. Fig. 6). Nevertheless, the performance of $\mathrm{CX} / \mathrm{CoFe}$ also decreases in the series of three CWPO experiments considered. Aiming to explain the interactions between cobalt and iron species responsible for the 
Table 3

Standard reduction potentials at $25{ }^{\circ} \mathrm{C}\left(E^{0}\right)$ for some half-reactions of interest $[31,32]$.

\begin{tabular}{lrl}
\hline Half-reaction & $E^{0}(\mathrm{~V})$ & \\
\hline $\mathrm{H}_{2} \mathrm{O}_{2} \rightleftarrows \mathrm{O}_{2}+2 \mathrm{H}^{+}+2 \mathrm{e}^{-}$ & -0.695 & $(4)$ \\
$\mathrm{Fe}^{2+}+2 \mathrm{e}^{-} \rightleftarrows \mathrm{Fe}$ & -0.447 & $(5)$ \\
$\mathrm{Co}^{2+}+2 \mathrm{e}^{-} \rightleftarrows \mathrm{Co}$ & -0.280 & $(6)$ \\
$\mathrm{Fe}^{3+}+\mathrm{e}^{-} \rightleftarrows \mathrm{Fe}^{2+}$ & 0.771 & $(7)$ \\
$\mathrm{H}_{2} \mathrm{O}_{2}+\mathrm{H}^{+}+\mathrm{e}^{-} \rightleftarrows \mathrm{HO}$ & 0.800 & $(8)$ \\
$\mathrm{Co}^{3+}+\mathrm{e}^{-} \rightleftarrows \mathrm{Ho}_{2} \mathrm{O}$ & 1.920 & $(9)$ \\
\hline
\end{tabular}

superior performance of $\mathrm{CX} / \mathrm{CoFe}$, but also for the partial catalyst deactivation observed, a detailed reaction mechanism is proposed in the following Section.

\subsubsection{Interactions between cobalt and iron species at the surface of the bimetallic $\mathrm{CX} / \mathrm{CoFe}$ catalyst}

In CWPO, the $\mathrm{H}_{2} \mathrm{O}_{2}$ molecule is decomposed via $\mathrm{HO} \bullet$ formation with the participation of reduced active sites/species (i.e., electron donor sites/species) existing at the surface of a catalyst [16]. In this sense, the electron donating capacity of $\mathrm{Fe}^{2+}$ is well recognized in CWPO. For the present experiments, the catalytic cycle is thought to be initiated through the redox reaction described in Eq. (1). In a more complex system, in which several metal species are present, the overall catalytic cycle is expected to be influenced by the redox potentials of each metal. With this in mind, the standard reduction potentials at $25^{\circ} \mathrm{C}\left(E^{0}\right)$ for half-reactions involving the metal species embedded in the magnetic carbon xerogels are compiled in Table 3 . The standard reduction potential of $\mathrm{H}_{2} \mathrm{O}_{2}$ decomposition via $\mathrm{HO}$ - formation is also given.

As observed in Table 3, the redox properties of cobalt and iron species are determined by the oxidation state in which they are present. Therefore, the identification and quantification of the oxidation state of each component existing at the surface of the magnetic carbon xerogels was performed by XPS analysis. Accordingly, the result of Fe $2 \mathrm{p}_{3 / 2}$ and Co $2 \mathrm{p}_{3 / 2}$ spectral fitting is shown in Fig. 7 . Regarding iron, the fit suggests a mix of $\mathrm{Fe}^{2+}$ and $\mathrm{Fe}^{3+}$ species both in $\mathrm{CX} / \mathrm{Fe}$ and $\mathrm{CX} / \mathrm{CoFe}$. In addition, the relative amount of each iron species is not particularly affected by the simultaneous inclusion of cobalt, as concluded from the inset of Fig. $7 \mathrm{a}$ and c. For cobalt, the fit of the $\mathrm{Co} 2 \mathrm{p}_{3 / 2}$ region suggests a mix Co, $\mathrm{Co}^{2+}$ and $\mathrm{Co}^{3+}$ species, both in $\mathrm{CX} / \mathrm{CoFe}$ and $\mathrm{CX} / \mathrm{Co}$. In this case, the relative amounts of each cobalt species are also not particularly affected by the simultaneous inclusion of iron, as concluded from the insets of Fig. 7e and g. It should be noted that metallic Co was undetectable in the XRD pattern of CX/CoFe [23], a phenomenon that may be ascribed to the interference of the less ordered graphic phase.

Once the composition of iron and cobalt species in each magnetic carbon xerogel is known, the half-reactions given in Table 3 were combined as shown in Table 4, aiming to obtain a reaction mechanism able to justify the superior performance of the bimetallic $\mathrm{CX} / \mathrm{CoFe}$ in CWPO, when compared to the performance of the monometallic $\mathrm{CX} / \mathrm{Fe}$ and $\mathrm{CX} / \mathrm{Co}$. In order to predict the feasibility of the proposed redox reactions, the reaction potentials at $25^{\circ} \mathrm{C}(E)$ are also given. As observed in Eq. (10), Fe is theoretically able to reduce $\mathrm{H}_{2} \mathrm{O}_{2}$ via $\mathrm{HO}$ formation. However, although Fe was detected by XRD analysis in our previous publication [23], it was undetected by XPS analysis both in $\mathrm{CX} / \mathrm{Fe}$ and $\mathrm{CX} / \mathrm{CoFe}$ (cf. Fig. 7a and c). This observation suggests that Fe particles are preferably surrounded by the organic phase during the synthesis of the magnetic carbon xerogels, therefore being less accessible to $\mathrm{H}_{2} \mathrm{O}_{2}$. As expected, the reaction potential obtained for the reaction described in Eq. (11) confirms the feasibility for the decomposition of $\mathrm{H}_{2} \mathrm{O}_{2}$ with the participation of reducing $\mathrm{Fe}^{2+}$ species. The $\mathrm{HO} \cdot$ radicals formed at the surface of the catalyst are afterwards expected to readily react with 4-NP molecules adsorbed nearby the HO radicals generation sites, resulting in the oxidation mechanism described in Section 3.2.1, and the high efficiency of TOC removal per unit of $\mathrm{H}_{2} \mathrm{O}_{2}$ decomposed shown in Fig. 4c. On the other hand, the reaction potential obtained for the reaction described in Eq. (12) suggests that $\mathrm{Co}^{2+}$ species are not active species for CWPO. In order to confirm this hypothesis, an additional CWPO run was performed with homogeneous $\mathrm{Co}^{2+}$ under the operating conditions given in Fig. 3. For that purpose, a relatively high amount of $\mathrm{Co}^{2+}$ was employed (126 $\mathrm{m} \mathrm{L} \mathrm{L}^{-1}$, corresponding to the total amount of $\mathrm{Co}^{2+}$ in the cobalt precursor included during the synthesis of $\mathrm{CX} / \mathrm{Co}$ and $\mathrm{CX} / \mathrm{CoFe}$ ). The 4$\mathrm{NP}$ and $\mathrm{H}_{2} \mathrm{O}_{2}$ conversions were null after $2 \mathrm{~h}$ of reaction (results not shown), confirming the theoretical prediction given in Table 4. The ability of metallic Co species to promote the formation of $\mathrm{HO}$ - from $\mathrm{H}_{2} \mathrm{O}_{2}$, as described by Eq. (13), was also considered. From a theoretical point of view, this reaction is spontaneous, with a high redox reaction potential. Nevertheless, when the results in Fig. 3 are analysed together with the results in Fig. 7, it is observed that the presence of metallic Co species cannot, by itself, explain the largely superior performance of $\mathrm{CX} / \mathrm{CoFe}$ in the CWPO of 4-NP, when compared to CX/Fe and CX/Co. As discussed before, $\mathrm{CX} / \mathrm{CoFe}$ possesses nearly the same amount of metallic Co species as $\mathrm{CX} / \mathrm{Co}$; on the other hand, the phase composition of iron species in $\mathrm{CX} / \mathrm{CoFe}$ is also about the same as in $\mathrm{CX} / \mathrm{Fe}$. However, the sum of the 4-NP removals obtained after $30 \mathrm{~min}$ of CWPO in the presence $\mathrm{CX} / \mathrm{Fe}$ and $\mathrm{CX} / \mathrm{Co}$ (i.e., $11.5 \%$ and $8.5 \%$, respectively, corresponding to a combined 4-NP removal of $20 \%$ ) is far below the 4-NP removal obtained in the presence of $\mathrm{CX} / \mathrm{CoFe}(98.5 \%)$. These results suggest that the reaction described in Eq. (13) is not the main mechanism responsible for the superior performance of CX/CoFe in CWPO.

Since the synergy arising from the simultaneous incorporation of cobalt and iron in the CX/CoFe catalyst cannot be fully ascribed to the direct interactions of iron and cobalt species with $\mathrm{H}_{2} \mathrm{O}_{2}$, particular attention was given to the interactions between $\mathrm{Fe}$ and Co species, which enables a faster regeneration of $\mathrm{Fe}^{2+}$ in the catalytic cycle. When there are only iron species, the $\mathrm{Fe}^{2+}$ regeneration from $\mathrm{Fe}^{3+}$ proceeds mainly through the reaction described by Eq. (2). However, several cobalt species are also present at the surface of the catalyst in addition to $\mathrm{Fe}^{2+}$ and $\mathrm{Fe}^{3+}$ when CX/CoFe is applied in CWPO. To evaluate the ability of $\mathrm{Co}^{2+}$ and $\mathrm{Co}$ species to promote $\mathrm{Fe}^{2+}$ regeneration from $\mathrm{Fe}^{3+}$, the reactions described by Eqs. (14) and (15) were considered. As observed, $\mathrm{Co}^{2+}$ species are unable to regenerate $\mathrm{Fe}^{2+}$ by reduction of $\mathrm{Fe}^{3+}$ (cf. Eq. (14)). On the other hand, the redox reaction of $\mathrm{Co}$ with $\mathrm{Fe}^{3+}$, leading to the regeneration of $\mathrm{Fe}^{2+}$ (cf. Eq. (15)), reveals a high reaction potential, thus being considered spontaneous. In order to confirm this hypothesis, both $\mathrm{CX} / \mathrm{Fe}$ and $\mathrm{CX} / \mathrm{CoFe}$ were collected after CWPO and characterized by XPS (cf. Fig. 7). As observed in Fig. 7a and b, the relative amount of iron species at the surface of $\mathrm{CX} / \mathrm{Fe}$ is unaffected by CWPO although the overall iron surface content decreases. This result was expected, since when $\mathrm{CX} / \mathrm{Fe}$ is applied in CWPO the catalytic cycle is mainly driven by Eqs. (2) and (3). On the opposite, when in the presence of cobalt species, the relative amount of $\mathrm{Fe}^{2+}$ at the surface of CX/CoFe increases from 42.1 to $54.0 \%$ upon its application in CWPO (cf. Fig. $7 \mathrm{c}$ and d), confirming the feasibility of the reaction described in Eq. (15). Therefore, it is possible to conclude that the reduction of $\mathrm{Fe}^{3+}$ in the CWPO process is more efficient when metallic Co is combined with iron species, such as in the surface of the bimetallic $\mathrm{CX} / \mathrm{CoFe}$ catalyst. This feature offers an alternative route to the reactions described by Eqs. (2) and (3), thus allowing to overcome one limiting step of the CWPO cycle with Fe species.

Summarizing, it can be concluded that the synergy arising from the simultaneous incorporation of cobalt and iron in the magnetic carbon xerogel catalyst denoted as $\mathrm{CX} / \mathrm{CoFe}$ can be ascribed to (i) the enhanced accessibility to the active iron species existing on the surface of $\mathrm{CX} /$ $\mathrm{CoFe}$, (ii) the ability of metallic Co species to catalyse $\mathrm{H}_{2} \mathrm{O}_{2}$ decomposition via $\mathrm{HO}$ - formation, and to (iii) the more efficient reduction of $\mathrm{Fe}^{3+}$ to $\mathrm{Fe}^{2+}$ promoted by Co species existing on the surface of $\mathrm{CX} /$ CoFe. The catalytic surface mechanism summarized in Fig. 8 accounts for the superior performance of the bimetallic iron-cobalt magnetic carbon xerogel ( $\mathrm{CX} / \mathrm{CoFe})$ in the CWPO of 4-NP, when compared to that of the monometallic $\mathrm{CX} / \mathrm{Fe}$. 

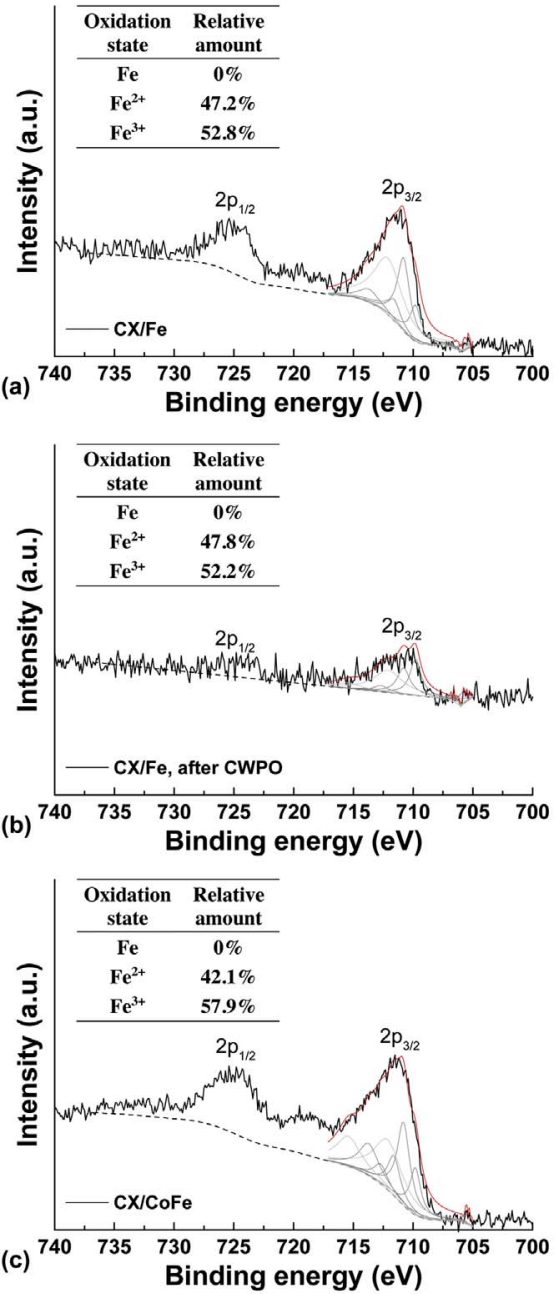

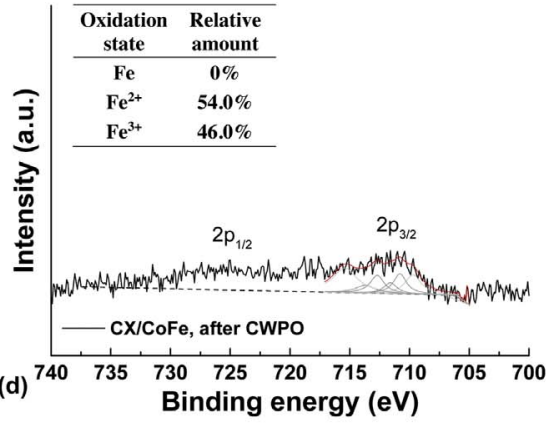

Fig. 7. Detailed XPS spectra of Fe $2 p$ region of ( $a$ and b) CX/ $\mathrm{Fe}$ and (c and d) CX/CoFe; and detailed XPS spectra of Co $2 \mathrm{p}$ region of (e and f) $\mathrm{CX} / \mathrm{CoFe}$ and $(\mathrm{g}) \mathrm{CX} / \mathrm{Co}$. XPS spectra obtained (a, c, e and $g$ ) before and (b, d and f) after CWPO runs performed during $24 \mathrm{~h}$ under the operating conditions given in Fig. 3. Inset: oxidation state of iron and cobalt species obtained from Fe $2 \mathrm{p}_{3 / 2}$ and Co $2 \mathrm{p}_{3 / 2}$ spectral fitting, respectively.
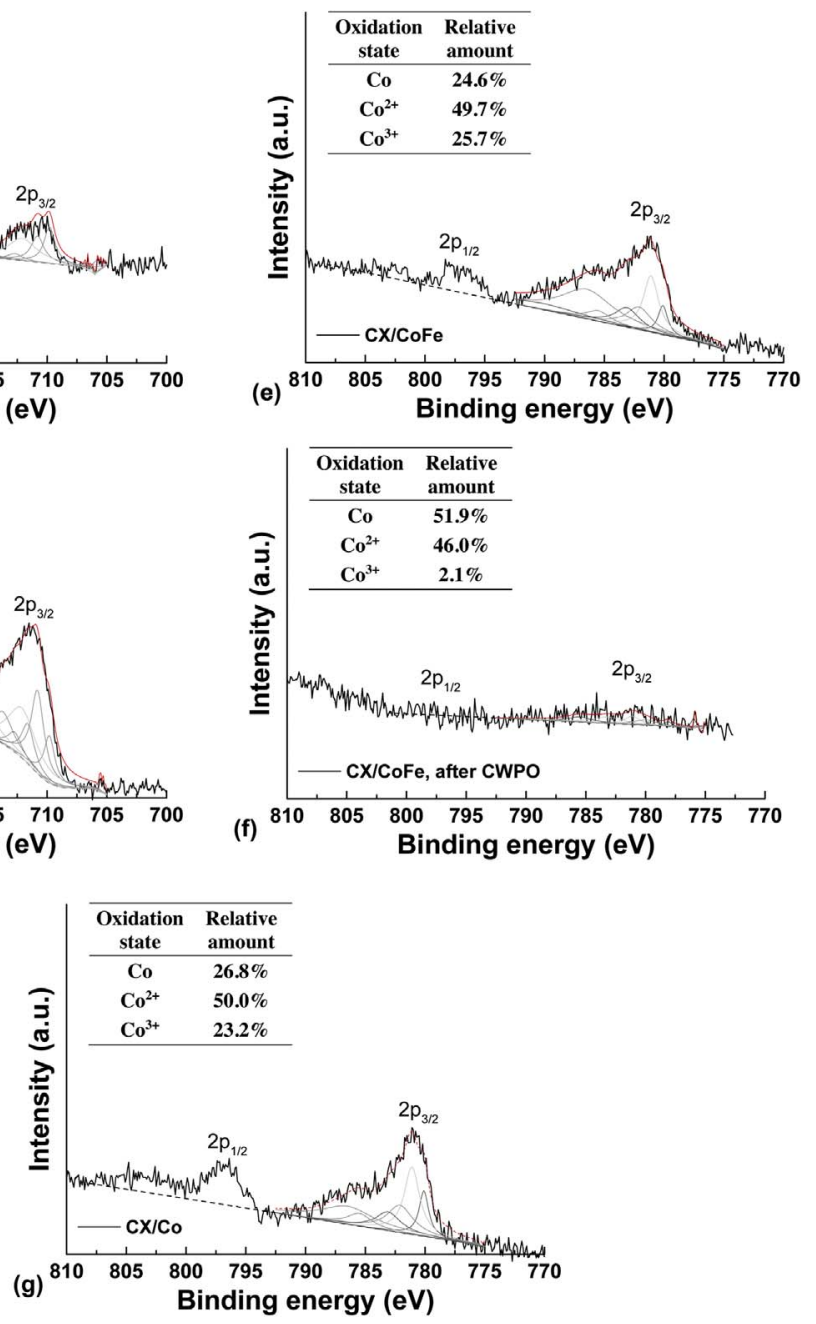

Table 4

Reaction potentials at $25{ }^{\circ} \mathrm{C}\left(E^{0}\right)$ for some reactions of interest.

\begin{tabular}{lrl}
\hline Reaction & $E^{o}(\mathrm{~V})$ & Comment \\
\hline $\mathrm{H}_{2} \mathrm{O}_{2}+\mathrm{Fe}+\mathrm{H}^{+} \rightarrow \mathrm{Fe}^{2+}+\mathrm{HO}^{\bullet}+\mathrm{H}_{2} \mathrm{O}+\mathrm{e}^{-}$ & 1.247 & Spontaneous \\
$\mathrm{H}_{2} \mathrm{O}_{2}+\mathrm{Fe}^{2+}+\mathrm{H}^{+} \rightarrow \mathrm{Fe}^{3+}+\mathrm{HO}^{\bullet}+\mathrm{H}_{2} \mathrm{O}$ & 0.029 & Spontaneous \\
$\mathrm{H}_{2} \mathrm{O}_{2}+\mathrm{Co}^{2+}+\mathrm{H}^{+} \rightarrow \mathrm{Co}^{3+}+\mathrm{HO}^{\bullet}+\mathrm{H}_{2} \mathrm{O}$ & -1.120 & Non-spontaneous \\
$\mathrm{H}_{2} \mathrm{O}_{2}+\mathrm{Co}^{+} \mathrm{H}^{+} \rightarrow \mathrm{Co}^{2+}+\mathrm{HO}^{\bullet}+\mathrm{H}_{2} \mathrm{O}+\mathrm{e}^{-}$ & 1.080 & Spontaneous \\
$\mathrm{Fe}^{3+}+\mathrm{Co}^{2+} \rightarrow \mathrm{Co}^{3+}+\mathrm{Fe}^{2+}$ & -1.149 & Non-spontaneous \\
$\mathrm{Fe}^{3+}+\mathrm{Co}^{2+} \mathrm{Co}^{2+}+\mathrm{Fe}^{2+}+\mathrm{e}^{-}$ & 1.051 & Spontaneous
\end{tabular}

Regarding the stability of the catalysts, as discussed in Section 3.2.2, the bimetallic $\mathrm{CX} / \mathrm{CoFe}$ catalyst reveals a better resistance against leaching of iron species to the treated water when compared to the monometallic $\mathrm{CX} / \mathrm{Fe}$. This increased stability of iron species can be ascribed to the presence of $\mathrm{Co}^{2+}$ in the structure of $\mathrm{CoFe}_{2} \mathrm{O}_{4}$ (i.e., the main iron oxide in $\mathrm{CX} / \mathrm{CoFe}$, as determined by XRD analysis in our previous publication [23]), rather than $\mathrm{Fe}^{2+}$ in $\mathrm{Fe}_{3} \mathrm{O}_{4}$ (i.e., in the case of $\mathrm{CX} / \mathrm{Fe}$ ). Briefly, magnetite possesses the chemical formula $\mathrm{Fe}^{2+} \mathrm{Fe}_{2}{ }^{3+} \mathrm{O}_{4}$; when $\mathrm{Co}^{2+}$ replaces $\mathrm{Fe}^{2+}$, cobalt ferrite with the general formula $\mathrm{Co}_{x} \mathrm{Fe}_{3-x} \mathrm{O}_{4}$ is obtained [30]. Under this context, Sileo et al. showed that the iron dissolution rate decreases with increasing $\mathrm{Co}^{2+}$ content in cobalt ferrites, through a complex process approximately described by a second-order kinetic model [30]. This observation was thoroughly explained in terms of electronic effects within the solid 


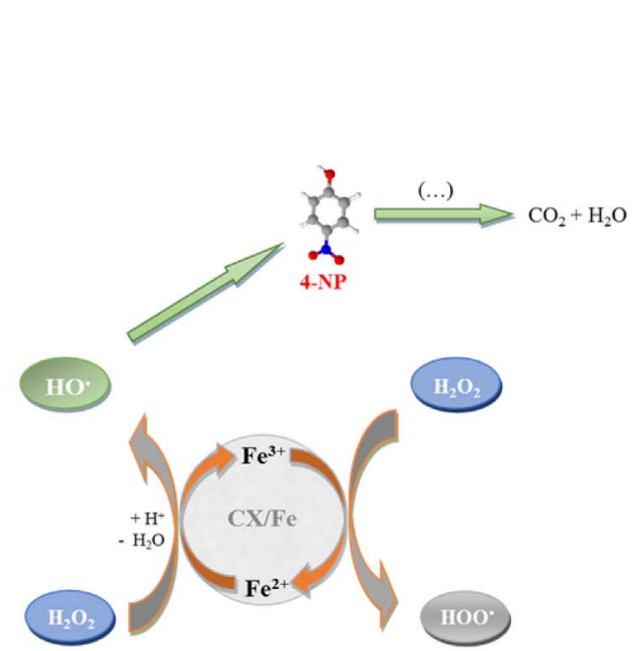

(a)

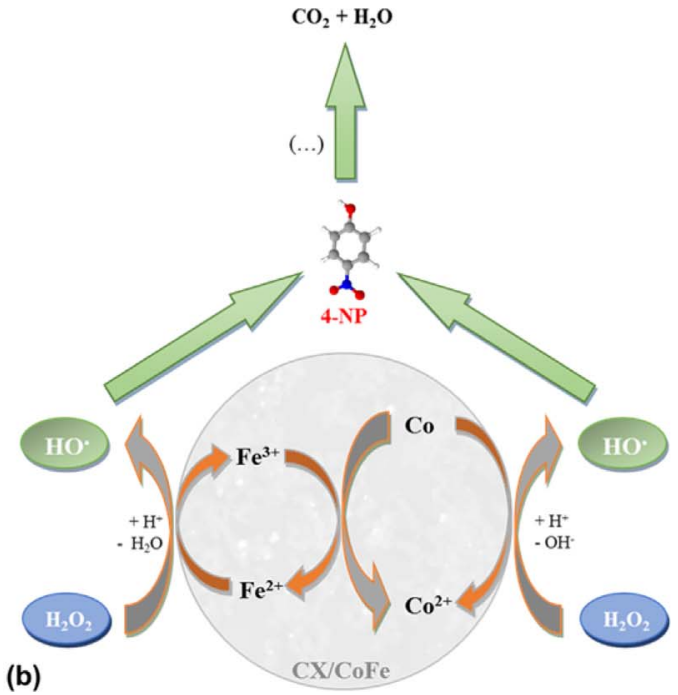

Fig. 8. Mechanism proposed for the surface catalytic reactions occurring on (a) $\mathrm{CX} / \mathrm{Fe}$ and (b) $\mathrm{CX} / \mathrm{CoFe}$. Bulk reactions between $\mathrm{HO}^{\bullet}$ radicals and 4-NP are also represented. framework, the most significant being the fast electron hopping between octahedral adjacent $\mathrm{Fe}^{2+} / \mathrm{Fe}^{3+}$ pairs occurring preferentially in magnetite. In this case, inner vicinal lattice $\mathrm{Fe}^{2+}$ accelerates the rate of $\mathrm{Fe}^{3+}$ reductive dissolution via internal electron hopping, whereas the amount of adjacent $\mathrm{Fe}^{2+} / \mathrm{Fe}^{3+}$ pairs is significantly lower in cobalt ferrite, thus yielding lower iron leaching rates. As depicted in Fig. 8b, metallic $\mathrm{Co}$ is oxidized to $\mathrm{Co}^{2+}$ both during the regeneration of $\mathrm{Fe}^{2+}$ active sites and the formation of $\mathrm{HO} \cdot$ from $\mathrm{H}_{2} \mathrm{O}_{2}$. The leaching of cobalt species to the treated water during the first CWPO cycle performed with $\mathrm{CX} / \mathrm{CoFe}$ amounts to $41.36 \mathrm{mg} \mathrm{L}^{-1}$ (cf. Fig. 6) - representing ca. $79 \mathrm{wt}$. $\%$ of the total content of cobalt initially embedded in the CX/CoFe catalyst. On the contrary, the cobalt leaching in the second and third CWPO cycles is rather low (0.93 and $0.23 \mathrm{mg} \mathrm{L}^{-1}$, respectively). These observations are in agreement with the mechanism proposed in Fig. 8. However, it is suggested that the leaching of cobalt species is the main cause of the partial catalyst deactivation observed in CWPO cycles performed with consecutive reuse of $\mathrm{CX} / \mathrm{CoFe}$. In order to infer about the propensity of cobalt species to undergo leaching from the surface of $\mathrm{CX} / \mathrm{CoFe}$ to the treated waters, the $\mathrm{CX} / \mathrm{CoFe}$ catalyst was collected after CWPO and analysed by XPS (cf. Fig. 7f). In comparison with the fresh sample (Fig. 7e), it was observed that the overall cobalt surface content decreases after CWPO. In addition, the relative amount of $\mathrm{Co}^{3+}$ species decreases significantly, maybe because they are preferably leached to water during CWPO; on the other hand, the relative amount of metallic Co increases substantially from 24.6 to $51.9 \%$, suggesting a higher resistance to leaching.

\section{Conclusions}

The bimetallic magnetic carbon xerogel containing cobalt and iron species embedded in its structure $(\mathrm{CX} / \mathrm{CoFe})$ revealed a much higher catalytic performance in the CWPO of highly concentrated 4-NP solutions than that expected from the performances of the monometallic catalysts containing only iron $(\mathrm{CX} / \mathrm{Fe})$ or cobalt $(\mathrm{CX} / \mathrm{Co})$. A clear synergy arises from the simultaneous incorporation of cobalt and iron into the carbon xerogels matrix. This effect was ascribed to (i) the enhanced accessibility to the active iron species existing at the surface of $\mathrm{CX} / \mathrm{CoFe}$ promoted by the simultaneous incorporation of cobalt, (ii) the ability of metallic Co species to catalyse the decomposition of $\mathrm{H}_{2} \mathrm{O}_{2}$ via $\mathrm{HO} \cdot$ formation, and to (iii) the more efficient reduction of $\mathrm{Fe}^{3+}$ to $\mathrm{Fe}^{2+}$ promoted by metallic Co species existing at the surface of $\mathrm{CX} / \mathrm{CoFe}$.

In addition, the bimetallic $\mathrm{CX} / \mathrm{CoFe}$ catalyst was also more stable in terms of leaching of iron species when compared to the monometallic $\mathrm{CX} / \mathrm{Fe}$. This increased stability of iron species was ascribed to the presence of $\mathrm{Co}^{2+}$ in the structure of $\mathrm{CoFe}_{2} \mathrm{O}_{4}$ (i.e., the main iron oxide in $\mathrm{CX} / \mathrm{CoFe}$ ), rather than $\mathrm{Fe}^{2+}$ in $\mathrm{Fe}_{3} \mathrm{O}_{4}$ (i.e., in the case of $\mathrm{CX} / \mathrm{Fe}$ ). As $\mathrm{Co}$ is oxidized during the regeneration of $\mathrm{Fe}^{2+}$ and the formation of $\mathrm{HO} \cdot$ from $\mathrm{H}_{2} \mathrm{O}_{2}$, it increases its susceptibility to undergo leaching to the treated waters. This was the main cause for the partial catalyst deactivation observed in CWPO cycles performed with consecutive reuse of $\mathrm{CX} / \mathrm{CoFe}$.

The deeper understanding of the interactions between iron and cobalt species, achieved through the results herein presented, opens future prospects for the development of bimetallic iron-cobalt magnetic carbon materials for CWPO applications.

\section{Acknowledgments}

This work was financially supported by: Project POCI-01-0145FEDER-006984 - Associate Laboratory LSRE-LCM funded by FEDER through COMPETE2020 - Programa Operacional Competitividade e Internacionalização (POCI) - and by national funds through FCT Fundação para a Ciência e a Tecnologia. R.S. Ribeiro acknowledges the individual Ph.D. grant SFRH/BD/94177/2013, with financing from FCT and the European Social Fund (through POPH and QREN). A.M.T. Silva acknowledges the FCT Investigator 2013 Programme (IF/01501/2013), with financing from the European Social Fund and the Human Potential Operational Programme.

\section{References}

[1] J.J. Pignatello, E. Oliveros, A. MacKay, Crit. Rev. Environ. Sci. Technol. 36 (2006) $1-84$.

[2] C.W. Jones, Applications of Hydrogen Peroxide and Derivatives, The Royal Society of Chemistry, Cambridge, UK, 1999.

[3] S. Morales-Torres, L.M. Pastrana-Martínez, J.L. Figueiredo, J.L. Faria, A.M.T. Silva, Environ. Sci. Pollut. Res. 19 (2012) 3676-3687.

[4] M. Umar, F. Roddick, L. Fan, H.A. Aziz, Chemosphere 90 (2013) 2197-2207.

[5] K.-H. Kim, S.-K. Ihm, J. Hazard. Mater. 186 (2011) 16-34.

[6] H. Särkkä, A. Bhatnagar, M. Sillanpää, J. Electroanal. Chem. 754 (2015) 46-56.

[7] L.W. Matzek, K.E. Carter, Chemosphere 151 (2016) 178-188.

[8] Z. Eren, J. Environ. Manage. 104 (2012) 127-141.

[9] P.V. Nidheesh, R. Gandhimathi, S.T. Ramesh, Environ. Sci. Pollut. Res. 20 (2013) 2099-2132.

[10] P.R. Gogate, A.B. Pandit, Adv. Environ. Res. 8 (2004) 501-551.

[11] S. Navalon, M. Alvaro, H. Garcia, Appl. Catal. B 99 (2010) 1-26.

[12] F. Haber, J. Weiss, Proc. R. Soc. Lond. A Math. Phys. Sci. 147 (1934) 332-351.

[13] M. Munoz, Z.M. de Pedro, J.A. Casas, J.J. Rodriguez, Appl. Catal. B 176-177 (2015) 249-265.

[14] W.G. Barb, J.H. Baxendale, P. George, K.R. Hargrave, Trans. Faraday Soc. 47 (1951) 462-500.

[15] W.G. Barb, J.H. Baxendale, P. George, K.R. Hargrave, Trans. Faraday Soc. 47 (1951) 591-616.

[16] R.S. Ribeiro, A.M.T. Silva, J.L. Figueiredo, J.L. Faria, H.T. Gomes, Appl. Catal. B 187 (2016) 428-460.

[17] P.V. Nidheesh, RSC Adv. 5 (2015) 40552-40577. 
[18] M. Muruganandham, R.P.S. Suri, M. Sillanpää, J.J. Wu, B. Ahmmad, S. Balachandran, M. Swaminathan, J. Nanosci. Nanotechnol. 14 (2014) 1898-1910.

[19] S. Rahim Pouran, A.A. Abdul Raman, W.M.A. Wan Daud, J. Cleaner Prod. 64 (2014) 24-35.

[20] M.C. Pereira, L.C.A. Oliveira, E. Murad, Clay Miner. 47 (2012) 285-302.

[21] A. Dhakshinamoorthy, S. Navalon, M. Alvaro, H. Garcia, ChemSusChem 5 (2012) 46-64.

[22] S. Navalon, A. Dhakshinamoorthy, M. Alvaro, H. Garcia, ChemSusChem 4 (2011) $1712-1730$

[23] R.S. Ribeiro, Z. Frontistis, D. Mantzavinos, D. Venieri, M. Antonopoulou, I. Konstantinou, A.M.T. Silva, J.L. Faria, H.T. Gomes, Appl. Catal. B 199 (2016) 170-186.

[24] M.C. Biesinger, B.P. Payne, A.P. Grosvenor, L.W.M. Lau, A.R. Gerson, R.S.C. Smart, Appl. Surf. Sci. 257 (2011) 2717-2730.

[25] R.S. Ribeiro, A.M.T. Silva, P.B. Tavares, J.L. Figueiredo, J.L. Faria, H.T. Gomes,
Catal. Today 280 (2017) 184-191.

[26] R.S. Ribeiro, A.M.T. Silva, L.M. Pastrana-Martínez, J.L. Figueiredo, J.L. Faria, H.T. Gomes, Catal. Today 249 (2015) 204-212.

[27] A. Di Paola, V. Augugliaro, L. Palmisano, G. Pantaleo, E. Savinov, J. Photochem. Photobiol. A 155 (2003) 207-214.

[28] Y. Liu, H.L. Liu, Y. Li, Appl. Catal. B 84 (2008) 297-302.

[29] M.A. Oturan, J. Peiroten, P. Chartrin, A.J. Acher, Environ. Sci. Technol. 34 (2000) 3474-3479.

[30] E.E. Sileo, L. García Rodenas, C.O. Paiva-Santos, P.W. Stephens, P.J. Morando, M.A. Blesa, J. Solid State Chem. 179 (2006) 2237-2244.

[31] D.R. Lide, CRC Handbook of Chemistry and Physics, 84th ed., CRC Press, Boca Raton, 2003.

[32] A. Armstrong David, E. Huie Robert, H. Koppenol Willem, V. Lymar Sergei, G. Merényi, P. Neta, B. Ruscic, M. Stanbury David, S. Steenken, P. Wardman, Pure Appl. Chem. 87 (2015) 1139-1150. 